\title{
Karasu Deresi'nde (İstanbul) Yaşayan Barbus cyclolepis Heckel, 1837 ve Gobio bulgaricus Drensky, 1926 (Teleostei) Türlerinin Bazı Büyüme Özellikleri
}

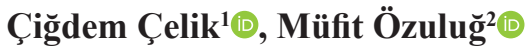

'İstanbul Üniversitesi, Fen Bilimleri Enstitüsü, İstanbul, Türkiye

${ }^{2}$ İstanbul Üniversitesi, Fen Fakültesi,

Biyoloji Bölümü, İstanbul, Türkiye

ORCID: Ç.Ç. 0000-0002-4443-4316; M.Ö. 0000-0002-1437-3890

Başvuru: 25.07.2021

Revizyon talebi: 14.08 .2021

Son revizyon teslimi: 02.09 .2021

Kabul: 02.09.2021

Sorumlu Yazar: Çiğdem Çelik

cidemmm_89@hotmail.com

Attf: Celik, C. ve Ozulug, M. (2021). Karasu Deresi'nde (İstanbul) Yaşayan Barbus cyclolepis Heckel, 1837 ve Gobio bulgaricus Drensky, 1926 (Teleostei) Türlerinin Bazı Büyüme Özellikleri. Turkish Journal of Bioscience and Collections, 5(2), 147-154. https://doi.org/10.26650/tjbc.2021974259
Öz

Amaç: Bu çalışmada Karasu Deresi'nde yaşayan Barbus cyclolepis Heckel, 1837 ve Gobio bulgaricus Drensky, 1926 türlerinin bazı büyüme özellikleri mevsimsel olarak incelenmiştir.

Materyal ve Yöntem: Örnekleme mevsimlik olarak (Ağustos 2017, Kasım 2017, Ocak 2018, Şubat 2018, Nisan 2018) elektroşok aracılığıyla gerçekleştirilmiştir. Her mevsimi temsil edecek örneklemeler arka arkaya 3 gün tekrarlanmıştır. Elde edilen B. cyclolepis ve G. bulgaricus bireylerinin boy, ağırlık, yaş, eşey dağılımları, yaş-boy, yaş-ağırlık, boyağırlık ilişkileri ve Fulton kondisyon faktörü değerleri incelenmiştir.

Bulgular: İncelenen B. cyclolepis bireyleri 0-III yaş gruplarındadır. Standart boy değerleri 3,5-13,5 cm; ağırlık değerleri ise 1,2232-50,8213 g arasında değişmiştir. Dişi:erkek oranı 1:0,94 olarak saptanmıştır. Tüm bireylerde; boy-ağırlık ilişkisi $\mathrm{W}=0,0253 * \mathrm{SL} 2,9226$ olarak belirlenmiştir. Yaşa göre en düşük kondisyon faktörü değeri, III yaş grubunda $(1,982)$ dişi bireylerde, en yüksek kondisyon faktörü değeri I yaş grubunda $(2,288)$ erkek bireylerde bulunmuştur. G. bulgaricus türünün yaş dağılımı ise I-IV yaş grupları arasında değişmektedir. Standart boy değerleri 2,5-9,6 cm; ağırlık değerleri ise 0,2989-18,3014 g arasında değişmiştir. Dişi:erkek oranı 1:1,56 olarak saptanmıştır. Tüm bireylerde; boyağırlık ilişkisi W= 0,0209*SL3,0081 olarak belirlenmiştir. Yaşa göre en düşük kondisyon faktörü değeri, II yaş grubunda $(1,950)$ erkek bireylerde, en yüksek kondisyon faktörü değeri IV yaş grubunda $(2,191)$ dişi bireylerde bulunmuştur.

Sonuç: Bu çalışma sonucunda Karasu deresinde yaşayan Barbus cyclolepis ve Gobio bulgaricus türlerinin kimi büyüme özellikleri ilk defa incelenmiştir.

Anahtar Kelimeler: Boy-ağırlık ilişkisi, büyüme, yaş, Cyprinidae, Gobionidae

Some Growth Characteristics of Barbus cyclolepis Heckel, 1837 and Gobio bulgaricus Drensky, 1926 (Teleostei) Species Living in Karasu Stream (Istanbul)

\section{Abstract}

Objective: In this study, some growth characteristics of Barbus cyclolepis Heckel, 1837 and Gobio bulgaricus Drensky, 1926 species living in Karasu Stream, were investigated. Materials and Methods: Sampling was carried out seasonal (August 2017, November 2017, January 2018, February 2018, April 2018) via electroshock. Samplings representing each season were repeated for 3 consecutive days. Lenght, weight, age, sex distributions and ratios, age-length, age-weight, length-weight relationships, Von Bertalanffy parameters, Fulton condition factor values of the obtained B. cyclolepis and G. bulgaricus individuals were analyzed.

Results: The examined B.cyclolepis individuals are in the 0-III age groups. Standard length values are $3.5-13.5 \mathrm{~cm}$; The weight values varied between $1.2232-50.8213 \mathrm{~g}$. The female: 
male ratio was determined as 1: 0.94. In all individuals; Length-weight relationship was determined as W=0.0253*SL2.9226. According to age, the lowest condition factor value was found in female individuals in the III age group (1.982), and the highest condition factor value was found in male individuals in the I age group (2.288).

The age distribution of G. bulgaricus species varies between I-IV age groups. Standard length values are 2.5-9.6 cm; The weight values varied between $0.2989-18.3014 \mathrm{~g}$. The female: male ratio was determined as 1:1.56. In all individuals; Length-weight relationship was determined as $\mathrm{W}=0.0209 *$ SL3.0081. According to age, the lowest condition factor value was found in male individuals in the II age group (1.950), and the highest condition factor value was found in female individuals in the IV age group (2.191).

Conclusion: As a result of this study, some growth characteristics of Barbus cyclolepis and Gobio bulgaricus species living in Karasu stream were investigated for the first time.

Keywords: Length-weight relationship, growth, age, Cyprinidae, Gobionidae

\section{Giriş}

Çok sayıdaki benzer türle temsil edilen coğrafik bölgeler söz konusu canlıların köken merkezi olarak kabul görmektedir. Cypriniformes takımının köken merkezinin Asya kıtası olduğu, çok sayıda türle temsil edildiği ve bu evrim merkezinden diğer coğrafi bölgelere dağılmış olduğu kabul edilmektedir (Winfield \& Nelson, 1991). Barbus ve Gobio cinsleri de çok sayıda temsilcisi olan Cypriniformes takımına aittir.

Barbus Cuvier, 1816 Cyprinidae familyasına ait orta ve büyük boylu türleri barındıran bir gruptur. Barbus cinsi; göl, geniş ve orta büyüklüklerdeki nehirlerden dağ sularına kadar çeşitli habitatlara adapte olmuş zemine yakın yaşamaya meyilli türleri içerir. $B$. cyclolepis türünün dağılım alanları; Yunanistan'ın doğusu, Bulgaristan'ın güneyi ve Türkiye'nin kuzeybatısındaki Arda, Tunca ve Ergene nehirleri gibi birçok büyük ve küçük kolun bağlandığı Meriç Nehri Havzası ile Marmara Havzası'nın kuzey kısımlarıdır (Korkmaz, 2017).

Gobionidae familyasina ait Gobio Cuvier, 1816 cinsi fenotipik çeşitlilik göstermesi nedeniyle özellikle taksonomi açısından zengin ve karmaşık bir gruptur ve bu nedenle de Avrupa'daki en değişken balık cinslerinden biri olarak kabul edilir (Bănărescu vd., 1999). Avrupa ve Asya'da tespit edilen 48 türü bulunmaktadır. Bu türlerden 15 'i Anadolu coğrafyasında dağılım göstermektedir (Aksu, 2020). Gobio cinsinin üyeleri kısa ömürlü türlerdir ve en fazla 8 yıla kadar yaşadıkları rapor edilmiştir (Maitland \& Campbell, 1992; Kottelat \& Freyhof, 2007). Ilıman özellik gösteren zemini taş ve çakıllarla kaplı hızlı akan nehir sistemlerinde yaşamaktadır (Kottelat \& Freyhof, 2007). G. bulgaricus bireyleri küçük gruplar halinde su kolonunun üst ve orta bölümlerinde yaşamaktadır. Türkiye, Bulgaristan, Yunanistan ve Makedonya'daki Meriç ve Aliakmon nehirleri ve kollarında dağılım göstermektedir (Kottelat \& Freyhof, 2007).
Aynı türün farklı bölgelerde yaşayan popülasyonlarının büyüme özelliklerinin ortaya konulması balıkçılık biyolojisi açısından önemli bir konudur. Çalışmanın konusunu oluşturan B. cyclolepis ve G. bulgaricus türlerinin büyüme özellikleri hakkında az sayıda araştırma bulunmaktadır (Rozdina $v d ., 2008$; Rozdina \& Raikova-Petrova, 2014; Saç \& Özuluğ, 2020). Her iki balık türü de dibe yakın yaşayarak çoğunlukla sedimandaki makroomurgasızlar ile beslenmektedir. Bu türler nehirlerin barbus zonu olarak bilinen kısımlarında yaşamını sürdürmektedirler. Çalışmanın yapıldığı Karasu Deresi'nde bu iki balık türünün büyüme özellikleri ile ilgili bir çalışma mevcut değildir. Bu çalışma Karasu Deresi'nde yaşayan B. cyclolepis ve $G$. bulgaricus türlerinin kimi büyüme özelliklerinin mevsimlik olarak incelenmesi amacıyla yapılmıştır.

\section{Materyal ve Yöntem}

Çalışma kapsamında Büyükçekmece Baraj-Gölü'ne dökülen derelerden biri olan Karasu Deresi'nde belirlenmiş bölgelerde mevsimlik olarak bir yıl boyunca arazi çalışması gerçekleştirilmiştir. Karasu Deresi, Çatalca-Silivri sınırında, İhsaniye Köyü doğusundan çıkar. Kuzeydoğudan güneybatıya doğru Kabakça ve İnceğiz köylerini batıda bırakıp küçük dereleri sularına katarak Büyükçekmece Baraj Gölü’ne dökülür. Karasu Deresi'nin uzunluğu 35 km'dir (Barutçu, 1995).

Balık örneklemeleri Karasu Deresi'nde İnceğiz piknik alanında belirlenen bir istasyonda her mevsim için seçilen ay içerisinde (Ağustos 2017, Kasım 2017, Ocak 2018, Şubat 2018 ve Nisan 2018) yapılmıştır. Seçilen bölgenin balıklarının daha iyi örneklenebilmesi için 3 gün arka arkaya aynı istasyona gidilerek avcılık tekrarlanmıştır. Dere, farklı zemin yapısına sahip (kum, taş, çamur) olmasına dikkat edilerek sı ̆ (derinlik 10-15 cm)-orta (derinlik 25-30 cm) 
ve derin (derinlik 55-60 cm) bölgelere ayrılmış ve avcıllk bu şekilde gerçekleştirilmiştir. Kış mevsiminde yapılan arazide elde edilen balık sayısı yetersiz olduğu için bu mevsimde 2 defa örnekleme yapılmıştır. Balık örneklerinin yakalanmasında portatif elektroşok cihazı kullanılmıştır. Yakalanan balıklar yüksek oranda anestezik madde (karanfil yağı) kullanılarak öldürülmüş ve buz kutusu içerisinde İstanbul Üniversitesi Biyoloji Bölümü Hidrobiyoloji Anabilim Dalı Laboratuvarı'na getirilerek incelenecekleri güne kadar $-18^{\circ} \mathrm{C}^{\prime}$ lik derin dondurucuda muhafaza edilmiştir. İncelenecekleri gün derin dondurucudan çıkarılarak oda sıcaklığında çözdürüldükten sonra total, çatal ve standart boyları $1 \mathrm{~mm}$ duyarlıklı boy ölçüm tahtası ile ölçülmüş, total vücut ağırlıkları $0,0001 \mathrm{~g}$ hassasiyetindeki elektronik terazide tartılmıştır. Çalışmada kullanılan analizler için balığın standart boy değerleri kullanılmıştır.

Dişi ve erkek bireylerin oranında istatistiksel açıdan farkın yorumlanabilmesi için ki-kare testi yapılmıştır. Yaş tayini için balığın pullarından yararlanılmıştır. Balıklardan alındıktan sonra zarflarda muhafaza edilen pullar, su yardımıyla yumuşatılıp temizlenmiştir. Temizlenen pullar suyu alınıp tam kurumadan önce 2 lam arasında sıkıştırılarak preparat haline getirilerek mikrofiş okuma cihazında incelenmiştir. Pullar gerçek ve yalancı yaş halkalarının ayırt edilmesine özen gösterilerek 2 farklı büyütmede (24X, 42X) iki farklı okuyucu tarafından farklı zamanlarda incelenmiş, iki okuyucunun ortak kararı ile balıkların yaşları belirlenmiştir (Duman \& Şen, 2002). Boy-Ağırlık ilişkisi incelemesinde $\mathrm{W}=\mathrm{aL}^{\mathrm{n}}$ şeklinde verilen allometrik büyüme denkleminden yararlanılmıştır (Le Cren, 1951). Bu formülde; W: Total vücut ağırlığı (g) ve L: Standart boy $(\mathrm{cm})$ değerlerini ve $\mathbf{n}$ : Boy-ağırlık ilişkisindeki regresyon sabitini göstermektedir. Boy ve ağırlık verileri, doğal logaritmaları (ln) kullanılarak $\ln \mathrm{W}=\operatorname{lna}+\mathrm{b} \operatorname{lnL}$ şeklindeki doğrusal forma dönüştürülmüş ve $a$ (eğimin y eksenini kestiği noktayı gösteren regresyon sabiti) ve $b$ (eğrinin eğimini gösteren regresyon katsayısı) değerleri hesaplanmıştır (King, 2007).
Total boy-çatal boy, total boy-standart boy, çatal boystandart boy arasındaki ilişkiyi göstermek için

$\mathrm{SL}=a \mathrm{TL} \pm b, \mathrm{SL}=a \mathrm{FL} \pm b, \mathrm{FL}=a \mathrm{TL} \pm b$ denklemleri kullanılmıştır [TL: Total boy (cm), FL: Çatal boy (cm), SL: Standart boy $(\mathrm{cm})]$.

Balık örneklerinin Fulton kondisyon faktörü (K) değerinin hesaplanmasında;

$\mathrm{K}=\left(\mathrm{W} / \mathrm{L}^{3}\right) 100$ eşitliğinden yararlanılmıştır (Bagenal, 1978). Bu eşitlikte W: Total vücut ağırlığı (g) ve L: Standart boy $(\mathrm{cm})$ değerlerini göstermektedir.

\section{Bulgular}

\section{Barbus cyclolepis}

Arazi çalışmaları sonucunda toplam 36 tanesi dişi $(\% 51,43)$, 34 tanesi ise erkek $(\% 48,57)$ toplam 70 adet $B$. cyclolepis bireyi elde edilmiştir. Dişi:erkek oranı 1:0,94 olarak bulunmuştur. Yapılan khi-kare testi sonucunda dişi ve erkek bireylerin oranında istatistiksel açıdan fark anlamlı bulunmamıştır $\left(X^{2}: 0,057 ; \mathrm{p}: 0,81 \mathrm{p}>0,05\right) .67$ bireyin pullarından yaş tayini yapılabilmiştir. Yaş tayini sonucunda balıkların 0 -III yaş grupları arasında dağılım gösterdiği belirlenmiştir (Tablo 1).

Tablo 1. Karasu Deresi'nden elde edilen B. cyclolepis bireylerinde yaş-eşey dağılımı.

\begin{tabular}{lcccccc}
\hline Yaş Grubu & \multicolumn{2}{c}{ Dişi } & \multicolumn{2}{c}{ Erkek } & \multicolumn{2}{c}{ Tüm Bireyler } \\
\hline & n & \% n & n & \% n & n & \% n \\
\hline 0 & - & - & 4 & 5,97 & 4 & 5,97 \\
I & 6 & 8,96 & 13 & 19,40 & 19 & 28,36 \\
II & 24 & 35,82 & 12 & 17,91 & 36 & 53,73 \\
III & 6 & 8,96 & 2 & 2,99 & 8 & 11,94 \\
Toplam & 36 & 53,73 & 31 & 46,27 & 67 & 100 \\
\hline
\end{tabular}

Tablo 2. Karasu Deresi'nden elde edilen B. cyclolepis bireylerinde yaş gruplarına göre, ortalama, en küçük ve en büyük boy değerleri.

\begin{tabular}{lccccccccc}
\hline & \multicolumn{4}{c}{ Dişi } & \multicolumn{4}{c}{ Erkek } & \multicolumn{2}{c}{ Tüm Bireyler } \\
\hline Yaş & $\mathbf{n}$ & $\mathbf{S L} \pm$ SD & Min.-Mak. SL & $\mathbf{n}$ & $\mathbf{S L} \pm$ SD & Min.-Mak. SL & $\mathbf{n}$ & SL \pm SD & Min.-Mak. SL \\
\hline $\mathbf{0}$ & - & - & - & 4 & $4,05 \pm 0,53$ & $3,5-4,5$ & 4 & $4,05 \pm 0,53$ & $3,5-4,5$ \\
I & 6 & $8,48 \pm 0,68$ & $7,5-9,4$ & 13 & $7,29 \pm 0,93$ & $5,4-8,5$ & 19 & $7,58 \pm 1,05$ & $5,4-9,4$ \\
II & 24 & $11,22 \pm 1,22$ & $8,0-13,1$ & 12 & $8,15 \pm 0,5$ & $7,3-9,0$ & 36 & $10,18 \pm 1,8$ & $7,3-13,1$ \\
III & 6 & $11,75 \pm 1,51$ & $9,5-13,5$ & 2 & $8,55 \pm 0,49$ & $8,2-8,9$ & 8 & $10,95 \pm 1,96$ & $8,2-13,5$ \\
Toplam & 36 & $10,85 \pm 1,60$ & $7,5-13,5$ & 31 & $7,22 \pm 1,50$ & $3,5-8,9$ & 67 & $9,17 \pm 2,39$ & $3,5-13,5$ \\
\hline
\end{tabular}

SL: Standart Boy (cm), SD: Standart Sapma 
Standart boy dağılımları incelendiğinde, dişi bireylerin 7,5-13,5 cm; erkek bireylerin 3,5-8,9 cm arasında; total vücut ağırlıkları incelendiğinde, dişi bireylerin 9,58-50,82 $\mathrm{g}$; erkek bireylerin 1,22-14,75 g; arasında değerlere sahip oldukları tespit edilmiştir. Yaşları okunan 67 bireyin yaş gruplarına göre boy değerleri Tablo 2'deki gibidir.

Yaşları okunan 67 adet bireyin yaş gruplarına göre vücut ağırlı̆g 1 değerleri ve standart sapmaları Tablo 3'te, 70 bireylere ait boy-ağırlık ilişkisi ve denklemlerine ait değerler Tablo 4 de verilmiştir.

B. cyclolepis bireyleri için total boy-çatal boy, total boy-standart boy ve çatal boy-standart boy ilişkilerini gösteren denklemler FL= 0,941TL-0,1719 $\left(\mathrm{r}^{2}=0,9989\right)$, $\mathrm{SL}=0,8808 \mathrm{FL}-0,0772\left(\mathrm{r}^{2}=0,9948\right), \mathrm{SL}=0,829 \mathrm{TL}-0,2287$ $\left(\mathrm{r}^{2}=0,9938\right)$ olarak hesaplanmıştır. İncelenen B. cyclolepis bireylerinin standart boy ve ağırlık değerleri kullanılarak Fulton kondisyon faktörü hesaplanmıştır. Tüm bireylerde yaşlara göre kondisyon faktörü değerleri incelendiğinde en düşük değere $(1,99)$ III yaş grubunda, en yüksek değere ise $(2,24) 0$ yaş grubunda rastlanmıştır (Tablo 5).

\section{Gobio bulgaricus}

Arazi çalışmaları sonucunda toplam 90 adet $G$. bulgaricus türü elde edilmiștir. Bunların içerisinde 34 tanesi diși (\% 37,78), 53 tanesi erkek (\% 58,89), 3 tanesi ise genç (\% 3,33) bireyden (juvenil) oluşmaktadır. Dişi:erkek oranı 1:1,56 olarak bulunmuştur. Yapılan khi-kare testi

Tablo 3. Karasu Deresi’nden elde edilen B. cyclolepis bireylerinde yaş gruplarına göre, en küçük ve en büyük ağırlık değerleri.

\begin{tabular}{lccccccccc}
\hline YAŞ & & \multicolumn{2}{c}{ Dişi } & \multicolumn{2}{c}{ Erkek } & \multicolumn{2}{c}{ Tüm Bireyler } \\
\hline & $\mathbf{n}$ & W \pm SD & Min.-Mak. W & $\mathbf{n}$ & W \pm SD & Min.-Mak. W & n & W \pm SD & Min.-Mak. W \\
\hline 0 & - & - & - & 4 & $1,43 \pm 0,25$ & $1,22-1,78$ & 4 & $1,43 \pm 0,25$ & $1,22-1,78$ \\
I & 6 & $12,19 \pm 2,31$ & $9,58-15,27$ & 13 & $9,20 \pm 3,17$ & $3,49-13,58$ & 19 & $10,00 \pm 3,25$ & $3,49-15,27$ \\
II & 24 & $31,70 \pm 10,11$ & $9,83-50,82$ & 12 & $11,62 \pm 2,41$ & $7,97-14,75$ & 36 & $24,99 \pm 12,71$ & $7,97-50,82$ \\
III & 6 & $33,65 \pm 12,77$ & $15,69-49,64$ & 2 & $12,66 \pm 2,89$ & $10,61-14,70$ & 8 & $28,40 \pm 14,56$ & $10,61-49,64$ \\
Toplam & 36 & $28,77 \pm 12,18$ & $9,58-50,82$ & 31 & $9,25 \pm 4,19$ & $1,22-14,75$ & 67 & $19,74 \pm 13,52$ & $1,22-50,82$ \\
\hline
\end{tabular}

W: Vücut ağırlığı/g, SD: Standart Sapma

Tablo 4. Karasu Deresi'nden elde edilen B. cyclolepis'in dişi, erkek ve tüm bireyleri için hesaplanan standart boy-vücut ağırlığı ilişkisi değerleri.

\begin{tabular}{|c|c|c|c|c|c|c|}
\hline Eşey & n & $\mathbf{a}$ & $\% 95$ GA & b & $\% 95$ GA & $\mathbf{r}$ \\
\hline Dişi & 36 & 0,019 & $\begin{array}{c}0,009- \\
0,038\end{array}$ & 3,0429 & $\begin{array}{c}2,746- \\
3,340\end{array}$ & 0,963 \\
\hline Erkek & 34 & 0,026 & $\begin{array}{c}0,018- \\
0,038\end{array}$ & 2,9033 & $\begin{array}{c}2,714- \\
3,093\end{array}$ & 0,984 \\
\hline $\begin{array}{l}\text { Tüm } \\
\text { Bireyler }\end{array}$ & 70 & 0,025 & $\begin{array}{c}0,020- \\
0,322\end{array}$ & 2,9226 & $\begin{array}{c}2,813- \\
3,032\end{array}$ & 0,988 \\
\hline
\end{tabular}

n: birey sayısı, a: kesișim noktası, b: eğim, \%95 GA: a ve b'nin \%95 güven aralığı değeri, r: korelasyon katsayısı

Tablo 5. Karasu Deresi'nden elde edilen B. cyclolepis bireylerinde yaşlara göre ortalama kondisyon değerleri.

\begin{tabular}{lccc}
\hline Yaş & Diş & Erkek & Tüm bireyler \\
\hline 0 & - & $2,24 \pm 0,63$ & $2,24 \pm 0,63$ \\
I & $1,99 \pm 0,25$ & $2,29 \pm 0,22$ & $2,23 \pm 0,28$ \\
II & $2,18 \pm 0,29$ & $2,13 \pm 0,21$ & $2,17 \pm 0,26$ \\
III & $1,98 \pm 0,17$ & $2,01 \pm 0,11$ & $1,99 \pm 0,15$ \\
\hline
\end{tabular}

Tablo 6. Karasu Deresi'nden elde edilen G. bulgaricus bireylerinde yaş-eşey dağılımı.

\begin{tabular}{lcccccccc}
\hline $\begin{array}{l}\text { Yaş } \\
\text { Grubu }\end{array}$ & \multicolumn{2}{c}{ Dişi } & Erkek & \multicolumn{2}{c}{ Genç Birey } & \multicolumn{2}{c}{$\begin{array}{c}\text { Tüm } \\
\text { Bireyler }\end{array}$} \\
\hline & $\mathbf{n}$ & $\mathbf{\%} \mathbf{n}$ & $\mathbf{n}$ & $\mathbf{\%} \mathbf{n}$ & $\mathbf{n}$ & $\mathbf{\%} \mathbf{n}$ & $\mathbf{n}$ & $\mathbf{\%} \mathbf{~ n}$ \\
\hline I & - & - & - & - & 3 & 3,33 & 3 & 3,33 \\
II & 5 & 5,56 & 8 & 8,89 & - & - & 13 & 14,45 \\
III & 21 & 23,33 & 32 & 35,56 & - & - & 53 & 58,89 \\
IV & 8 & 8,89 & 13 & 14,44 & - & - & 21 & 23,33 \\
Toplam & 34 & 37,78 & 53 & 58,89 & 3 & 3,33 & 90 & 100 \\
\hline & & & & & & & &
\end{tabular}

sonucunda dişi ve erkek bireylerin oranında istatistiksel açıdan fark anlamlı bulunmuştur $\left(X^{2}: 4,149 ; \mathrm{p}: 0,042 \mathrm{p}<\right.$ $0,05)$. Yaş tayini 90 bireyin pulları incelenerek yapılmıştır. Yaş tayini sonucunda balıkların I-IV yaş grupları arasında dağılım gösterdiği belirlenmiştir (Tablo 6).

Standart boy dağılımları incelendiğinde, dişi bireylerin 4,9-9,6 cm; erkek bireylerin 5,4-9,2 cm, genç bireylerin ise $2,5-4,5 \mathrm{~cm}$ arasında; total vücut ağırlıkları 
Tablo 7. Karasu Deresi'nden elde edilen G. bulgaricus bireylerinde yaş gruplarına bağlı ortalama, en küçük ve en büyük boy değerleri.

\begin{tabular}{lccccccccc}
\hline & \multicolumn{3}{c}{ Dişi } & \multicolumn{2}{c}{ Erkek } & \multicolumn{3}{c}{ Tüm Bireyler } \\
\hline Yaş & $\mathbf{n}$ & SL \pm SD & Min.-Mak. SL & $\mathbf{n}$ & SL \pm SD & Min.-Mak. SL & n & SL \pm SD & Min.-Mak. SL \\
\hline I & - & - & - & - & - & - & 3 & $3,43 \pm 1,01$ & $2,5-4,5$ \\
II & 5 & $5,92 \pm 0,66$ & $4,9-6,5$ & 8 & $6,29 \pm 0,8$ & $5,4-7,5$ & 13 & $6,15 \pm 0,75$ & $4,9-7,5$ \\
III & 21 & $7,25 \pm 0,67$ & $6,2-8,7$ & 32 & $7,68 \pm 0,59$ & $6,5-9,2$ & 53 & $7,51 \pm 0,65$ & $6,2-9,2$ \\
IV & 8 & $8 \pm 0,9$ & $6,9-9,6$ & 13 & $8,27 \pm 0,55$ & $7,5-9,2$ & 21 & $8,17 \pm 0,69$ & $6,9-9,6$ \\
Toplam & 34 & $7,23 \pm 0,95$ & $4,9-9,6$ & 53 & $7,61 \pm 0,86$ & $5,4-9,2$ & 90 & $7,33 \pm 1,16$ & $2,5-9,6$ \\
\hline
\end{tabular}

SL: Standart Boy/cm, SD: Standart Sapma

Tablo 8. Karasu Deresi’nden elde edilen G. bulgaricus bireylerinde yaş gruplarına bağlı ortalama, en küçük ve en büyük ağırlık değerleri.

\begin{tabular}{lccc|ccccccc}
\hline & \multicolumn{4}{c}{ Dişi } & \multicolumn{2}{c}{ Erkek } & \multicolumn{2}{c}{ Tüm Bireyler } \\
\hline Yaş & $\mathbf{n}$ & $\mathbf{W} \pm$ SD & Min.-Mak. W & $\mathbf{n}$ & $\mathbf{W} \pm$ SD & Min.-Mak. W & $\mathbf{n}$ & W \pm SD & Min.-Mak. W \\
\hline I & - & - & - & - & - & - & 3 & $0,97 \pm 0,78$ & $0,30-1,82$ \\
II & 5 & $4,45 \pm 1,01$ & $2,71-5,29$ & 8 & $4,90 \pm 1,5$ & $3,13-7,55$ & 13 & $4,73 \pm 1,3$ & $2,71-7,55$ \\
III & 21 & $8,16 \pm 2,05$ & $4,98-12,14$ & 32 & $9,97 \pm 2,36$ & $6,14-17,49$ & 53 & $9,25 \pm 2,4$ & $4,98-17,49$ \\
IV & 8 & $11,57 \pm 3,95$ & $6,64-18,30$ & 13 & $12,34 \pm 2,51$ & $9,02-17,22$ & 21 & $12,05 \pm 3,06$ & $6,64-18,30$ \\
Toplam & 34 & $8,42 \pm 3,29$ & $2,71-18,30$ & 53 & $9,78 \pm 3,23$ & $3,13-17,49$ & 90 & $8,97 \pm 3,57$ & $0,30-18,30$ \\
\hline
\end{tabular}

W: Vücut ağırlı̆̆ı/g, SD: Standart Sapma

Tablo 9. Dişi, erkek ve tüm G. bulgaricus bireyleri için hesaplanan standart boy-vücut ağırlığı ilişkisi değerleri.

\begin{tabular}{lccccccc}
\hline Eşey & $\mathbf{n}$ & $\mathbf{a}$ & $\mathbf{\%}$ 95 GA & b & \% 95 GA & r \\
\hline Dişi & 34 & 0,0324 & $0,017-0,060$ & 2,7867 & $2,474-3,100$ & 0,955 \\
Erkek & 53 & 0,0195 & $0,012-0,032$ & 3,0424 & $2,791-3,2940$ & 0,959 \\
Tüm Bireyler & 90 & 0,0209 & $0,016-0,026$ & 3,0081 & $2,889-3,128$ & 0,983 \\
\hline
\end{tabular}

n: birey sayısı, a: kesişim noktası, b: eğim, \%95 GA: a ve b'nin \%95 güven aralı̆̆ı değeri, r: korelasyon katsayısı

incelendiğinde, dişi bireylerin 2,71-18,30 g; erkek bireylerin 3,13-17,49 g; genç bireylerin ise 0,30-1,82 $\mathrm{g}$ arasında değerlere sahip oldukları tespit edilmiştir. Yaşları okunan 90 bireyin yaş gruplarına göre boy ve ağırlık Tablo 7 ve 8 'de verilmiştir.

İncelenen bireylere ait boy-ağırlık ilişkisi ve denklemlerine ait değerler Tablo 9 da verilmiştir.

G. bulgaricus bireyleri için total boy-çatal boy, total boy-standart boy ve çatal boy-standart boy ilişkilerini gösteren denklemler $\mathrm{FL}=0,9451 \mathrm{TL}-0,0941\left(\mathrm{r}^{2}=0,9951\right)$, $\mathrm{SL}=0,8247 \mathrm{TL}-0,0602\left(\mathrm{r}^{2}=0,9784\right), \mathrm{SL}=0,8723 \mathrm{FL}+0,024$ $\left(\mathrm{r}^{2}=0,9827\right)$ olarak hesaplanmıştır.

İncelenen tüm $G$. bulgaricus bireylerinin standart boy ve ağırlık değerleri kullanılarak Fulton kondisyon faktörü
Tablo 10. Karasu Deresi'nden elde edilen tüm G. bulgaricus bireylerinde yaşlara göre ortalama kondisyon değerleri.

\begin{tabular}{lccc}
\hline Yaş & Dişi & Erkek & Tüm Bireyler \\
\hline I & - & - & $2,03 \pm 0,13$ \\
II & $2,15 \pm 0,35$ & $1,95 \pm 0,28$ & $2,03 \pm 0,31$ \\
III & $2,12 \pm 0,25$ & $2,18 \pm 0,21$ & $2,15 \pm 0,23$ \\
IV & $2,19 \pm 0,23$ & $2,16 \pm 0,13$ & $2,17 \pm 0,17$ \\
\hline
\end{tabular}

hesaplanmıştır. Tüm bireylerde yaşlara göre kondisyon faktörü değerleri incelendiğinde en düşük değere $(2,03)$ II yaş grubunda, en yüksek değere ise $(2,17)$ IV yaş grubunda rastlanmıştır (Tablo 10). 


\section{Tartışma ve Sonuç}

Küçük boylu balıklarla ilgili çalışmalar genellikle ihmal edilmektedir. Bunun başlıca nedeni ticari önemlerinin olmamasıdır (Mastrorillo vd., 1997). Çalışma konusunu oluşturan B. cyclolepis ve özellikle G. bulgaricus bu türler arasında bulunmaktadır. Oysa ki, B. cyclolepis türü 25 $\mathrm{cm}, G$. bulgaricus ise $9,5 \mathrm{~cm}$ boya kadar rapor edilmiştir (Kottelat \& Freyhof, 2007, Saç \& Özuluğ 2020).

B. cyclolepis in Yunanistan'da (Makedonya'da bulunan iki dere üzerinde) yaşayan bir populasyonunda yapılan çalışmada erkek bireylerde 6 yaş grubu $(0+$ dan $5+$ ya), dişilerde ise 10 yaş grubu $(0+$ dan $9+$ ya) na rastlanmıştır. Maksimum total boy erkeklerde $163 \mathrm{~mm}$ ( $5+$ yaş), dişilerde ise $244 \mathrm{~mm}(9+)$ ölçülmüş; dişi:erkek oranı 1:1,28 olarak tespit edilmiştir $\left(X^{2}=5,04 ; \mathrm{p}<0,05\right)$. Populasyonda erkek bireyler baskındır ve dişi: erkek oranında istatistiksel açıdan fark anlamlıdır. Kondisyon Faktörü değerleri ise ilkbaharda artmış ve aşamalı olarak yaz boyunca azalmış, kış sonunda ise tekrar giderek artmaya başlamıştır (Vasiliou \& Economidis, 2005).

Meriç Nehri'nde besin çeşitliliği üzerinde yapılmış bir çalışmada Nisan-Kasım 2006 ayları boyunca 43'ü erkek, 51'i dişi, 2'si juvenil, 5'i de cinsiyeti tespit edilemeyen bireyler olmak üzere toplam 101 birey incelenmiştir (Rozdina $v d ., 2008$ ). Yine Meriç Nehri'nde büyüme özellikleri ilgili yapılmış bir diğer çalışmaya göre, Eylül 2005-Haziran 2007 tarihleri arasında 847 birey yakalanmış ve 8 yaş grubuna (1-8) rastlanmıştır. Boy-ağırlık ilişkisi formülü $\mathrm{W}=0,0144 * \mathrm{~L}^{3,0588}$ olarak verilmiştir (Rozdina \& Raikova-Petrova, 2014).

Struma Nehri üzerinde yaş, büyüme oranları ve kondisyon faktörü hakkında yapılmış bir çalışmaya göre 2006'dan 2011'e kadar elektroşok ile avcılık yapılmış ve 537 birey yakalanmıştır. Populasyonun 6 yaş grubundan (1'den 6'ya) oluştuğu, 3. yaş grubunun ve 61-70 mm aralığındaki (SL) boy grubunun baskın olduğu bildirilmiştir. Avlanan en uzun birey $245 \mathrm{~mm}$, en ağır birey ise $146 \mathrm{~g}$ (5 yaş grubunda) dır. Boy-ağırlık ilişkisi formülü $\mathrm{W}=0,0002 * \mathrm{~L}^{2,896}$ olarak belirlenmiştir (Raikova \& Kolev, 2015).

Yaptı̆̆ımız çalışmada khi-kare testi sonucunda dişi ve erkek bireylerin oranındaki fark istatistiksel açıdan anlamlı bulunmamıştır $\left(X^{2}=0,057\right.$; p: $\left.0,81 \mathrm{p}>0,05\right)$, bu yönden bulgularımız Vasiliou \& Economidis, 2005'in yaptı ğ çalışmadan farklılık göstermektedir.

$\mathrm{Bu}$ çalışmada incelenen bireylerde yaş dağılımı 0-III (4 yaş grubu) aralığındadır. Baskın grup II. yaş grubudur. III. yaş grubundan daha yaşlı bireylere rastlanmamış olmasını çalışma yapılan bölgenin çok derin olmayan bir dere olmasına dayanabilir. Önceki çalışmalar ile bu çalışmadaki kimi bulguların farklı olmasının nedenini ise incelediğimiz balıkların yaşça küçük olmaları ile ilgili olduğuna bağlanabilir.

Boy-ağırlık ilişkisi tüm bireyler için $\mathrm{W}=0,0253 * \mathrm{SL}^{2,9226}$ olarak belirlenmiştir, izometrik büyüme tespit edilmiştir. Yakın bölgelerdeki popülasyonlara ait verilerle karşılaştırması Tablo 11 de verilmiştir.

Yaşlara göre kondisyon faktörü değerleri en düşük III yaş grubunda en yüksek ise 0 yaş grubunda hesaplanmıştır. Kondisyon faktörü değerleri; çalışma yapılan tarihe, çalışma alanının ekolojik özelliklerine, çalışılan mevsime, balığın yaşadığı alanda beslendiği besin tipine bağlı olarak değişkenlik gösterebilir. Kondisyon faktörü değerlerinin küçük boylu bireylerde en düşük olması, artan yaşla birlikte artması beklenir. Fakat yapılan bu çalışmada birey sayılarının az olması ve yaşa göre dengesiz dağılım

Tablo 11. Farklı habitatlardaki B.cyclolepis ve G. bulgaricus ta boy-ağırlık ilişkisi parametreleri.

\begin{tabular}{lcccc}
\hline Tür & $\mathbf{n}$ & $\mathbf{a}$ & $\mathbf{b}$ & Kaynak \\
\hline & 847 & 0,0144 & 3,0588 & $\begin{array}{c}\text { Rozdina \& } \\
\text { Raikova-Petrova, } \\
2014\end{array}$ \\
$\begin{array}{lcccc}\text { Barbus } \\
\text { cyclolepis }\end{array}$ & 537 & 0,0002 & 2,896 & $\begin{array}{c}\text { Raikova \& Kolev, } \\
2015\end{array}$ \\
& 70 & 0,0253 & 2,9226 & Bu çalışma \\
\hline $\begin{array}{l}\text { Gobio } \\
\text { bulgaricus }\end{array}$ & 883 & 0,0174 & 3,1179 & Saç, 2017 \\
\hline
\end{tabular}

sebebiyle bulunan değerler beklenen değerlerden farkl111k göstermiştir. Ayrıca bu duruma artan yaşla birlikte yavaşlayan metabolizma hızının da sebep olabileceği düşünülmektedir (Saç, 2017).

G. bulgaricus ile ilgili yapılmış çalışmalar incelendiğinde ise sonuçlar şu şekildedir:

Istranca Deresi (İstanbul)'nde biyoekolojik özellikleri üzerine yapılan bir çalışmada Mart 2012- Haziran 2013 tarihleri arasında 883 adet birey yakalanmıştır. Dişi:erkek oranı 1:1,18 olarak bulunmuştur. Dişi ve erkek bireylerin oranında istatistiksel olarak anlamlı bir fark bulunmuştur $\left(X^{2}=4,88 ; p<0,05\right)$ ve erkek bireyler baskındır. Standart boy değerleri 2,0 ile 9,8 $\mathrm{cm}$ arasında iken, ağırlık değerleri 0,1365 ile 22,4292 $\mathrm{g}$ arasındadır. Türün yaş dağılımı 0 ve $\mathrm{V}$ yaş olarak bulunmuştur. III. yaş grubu baskındır. Boyağırlık ilişkisi $\mathrm{W}=0,0174 * \mathrm{~L}^{3,1179}$ şeklinde hesaplanmıştır. Tüm bireyler için en düşük ve en yüksek kondisyon 
faktörü değerleri sırasıyla 0 ve $\mathrm{V}$ yaş grubunda olarak belirlenmiştir. Artan yaş ile birlikte kondisyon faktörü değerinin de arttığı gözlenmiştir (Saç, 2017).

$\mathrm{Bu}$ çalışmada 90 adet birey elde edilmiş olup bunlardan 34'ü dişi, 53'ü erkek ve 3'ü de genç bireydir. Dişi:erkek oranı 1:1,56 olarak tespit edilmiştir. Dişi ve erkek bireylerin oranında istatistiksel açıdan fark anlamlı bulunmuştur $\left(X^{2}=\right.$ 4,149; p: 0,042 p < 0,05). Erkek bireyler baskındır. Dişierkek oranının doğada 1:1 olması beklenir. Bu oranda meydana gelecek değişimler ilgili türün bulunduğu ortamda üreme stratejisi açısından bir adaptasyon gösterdiği şeklinde yorumlanabilir (Gaygusuz, 2012).

I-IV aralığında 4 yaş grubu saptanmıştır; baskın olan III. yaş grubudur. Bu yönden Istranca Deresi'nde Saç, 2017 tarafından yapılan çalışma ile benzer sonuçlar göstermektedir. IV yaş grubundan daha yaşlı bireylere rastlanmamış olması Gobio cinsi üyelerinin kısa ömürlü balıklar olmalarından kaynaklanmaktadır.

Boy-ağırlık ilişkisi tüm bireyler için $\mathrm{W}=0,0209 * \mathrm{SL}^{3,0081}$ olarak belirlenmiştir, izometrik büyüme tespit edilmiştir. Yaşlara göre en düşük ve en yüksek kondisyon faktörü değerleri II. ve IV. yaş grubunda bulunmuştur. Bu da balığın yaşının büyüdükçe iyi beslenip boy ve ağırlı̆̆ını geliştirmesiyle yani besililik durumuyla alakalıdır.

Ticari değeri olmayan küçük boylu ve kısa yaşam döngüsüne sahip bu tür balıklarla ilgili ülkemiz iç sularında yapılmış çok fazla bir çalışmaya rastlanmamıştır. Mevcut çalışmanın literatüre katkı sağlaması umulmaktadır.

Hakem Değerlendirmesi: Dış bağımsız.

Çıkar Çatışması: Yazarlar çıkar çatış̧ası bildirmemiştir. Finansal Destek: Bu çalışma İstanbul Üniversitesi Bilimsel Araştırma Projeleri Koordinasyon Birimi (27213) tarafından desteklenmiştir.

Yazar Katkıları: Konsept ve dizayn çalışması: Ç.Ç., M.Ö.; Veri Toplama: Ç.Ç., M.Ö.; Veri Analizi/Yorumlama: Ç.Ç., M.Ö.; Makale Taslağı: Ç.Ç., M.Ö.; Makalenin Eleştirel Revizyonu: M.Ö.; Nihai Onay ve Sorumluluk: Ç.Ç., M.Ö.; Teknik ve Materyal Desteği: Ç.Ç., M.Ö.; Son Kontol: M.Ö. Peer-review: Externally peer-reviewed.

Conflict of Interest: The authors declare that they have no conflicts of interest.

Financial Disclosure: This study was supported by Istanbul University Scientific Research Projects Coordination Unit (27213).

Author Contributions: Conception/Design of study: Ç.Ç., M.Ö.; Data Acquisition: Ç.Ç., M.Ö.; Data Analysis/ Interpretation: Ç.Ç., M.Ö.; Drafting Manuscript: Ç.Ç., M.Ö.; Critical Revision of Manuscript: M.Ö.; Final
Approval and Accountability: M.Ö.Ç.Ç., M.Ö.

\section{Kaynakça/References}

Aksu, İ. (2020). Türkiye İç Sularında Dağılım Gösteren Gobio Cuvier,1816 Cinsine Ait Türlerin Filogenetik Analizi. Doktora Tezi, Recep Tayyip Erdoğan Üniversitesi, Fen Bilimleri Enstitüsü.

Bagenal, T. (1978). Methods for Assessment of Fish Production in Freshwaters. Blackwell Scientific Publications, London.

Bănărescu, P.M. (1999). Gobio Cuvier, 1816. In: The freshwater fishes of Europe. Vol. 5/I. Cyprinidae 2. Part 1. Rhodeus to Capoeta. Bănărescu P. M. (ed.), pp. 33-36, AULA Verlag, Wiebelsheim.

Barutçu,S. (1995). Karasu Havzasında Ziraat Hayatı. Yüksek Lisans Tezi, İstanbul Üniversitesi, Sosyal Bilimler Enstitüsü.

Bertalanffy, L.V. (1957). Quantitative Lows in Metabolism and Growth. The Quarterly Review of Biology, 32 (3), 217-231.

Duman, E. \& Şen, D. (2002). Keban Baraj Gölü'nde Yaşayan Carassius auratus (L.,1758)' da Karşıllaştırmalı Yaş Tayini. G. Ü. Gazi Eğitim Fakültesi Dergisi, 22, (3), 1-9.

Gaygusuz, Ö. (2012). Darlık Barajına Akan Bazı Derelerde Cyprinidae Familyasına Ait İki Türün Biyoekolojik Özellikleri. Doktora Tezi, İstanbul Üniversitesi, Fen Bilimleri Enstitüsü.

King, M. (2007). Fisheries Biology, Assesment and Management. Fishing News Book, Blackwell Publishing Ltd, Singapore. 9781-4051-5831-2.

Korkmaz, M. (2017). Türkiye'de Yayılış Gösteren Barbus (Pisces: Cyprinidae) Türlerinin Coğrafik Varyasyonlarının Araştırılması. Doktora Tezi, Hacettepe Üniversitesi, Fen Bilimleri Enstitüsü.

Kottelat, M. \& Freyhof, J. (2007). Handbook of European freshwater fishes. Publications Kottelat, Cornol and Freyhof, Berlin.

Le Cren, E.D. (1951). The Lenght-Weight Relationships and Seasonal Cycle in Gonad Weight and Condition in Perch (Percaf luviatilis). Journal of Animal Ecology, 20, 210-219.

Maitland, P.S. \& Campbell, R.N. (1992). Freshwater fishes of the British Isles. Harper Collins Publishers, London.

Mastrorillo, S., Lek, S., Dauba \& F., Belaud, A. (1997). The use of artificial neural networks to predict the presence of small-bodied fish in a river. Freshwater Biology, 38, 237- 246.

Raikova, G. \& Kolev, V. (2015). Age, Growth Rate And Condition Factor Of The Maritsa Barbel (Barbus cyclolepis Heckel, 1837) In The Stryama River. Forestry Ideas, (2): 277-283 .

Rozdina, D., Raikova-Petrova, G., Marinova, R. \& Uzunova, E. (2008). Food Spectrum And Feeding Of Barbus cyclolepis Heckel From The Middle Stream Of Maritza River (Bulgaria). Bulgarian Journal of Agricultural Science, 14 (2), 209-213. 
Rozdina, D.A. \& Raikova-Petrova, G.N. (2014). Growth Rate of Barbus cyclolepis (Cyprinidae) in the Middle Stream of the Maritsa River, Bulgaria. Acta Zoologica Bulgarica, 66 (2), 265-270.

Saç, G. (2017). Istranca Deresi (İstanbul) Balıklarının Dağılımı ve İki Türün Biyoekolojik Özellikleri. Doktora Tezi, İstanbul Üniversitesi, Fen Bilimleri Enstitüsü.
Saç, G. \& Özuluğ, M. (2020). Life history pattern and feeding habits of Gobio bulgaricus (Drensky, 1926) (Pisces: Gobionidae) in an endorheic stream (Istranca Stream, Turkey). Iranian Journal of Fisheries Sciences, 19(1), 248-261.

Vasiliou, A \& Economidis, P.S. (2005). On the life-history of Barbus peloponnesius and Barbus cyclolepis in Macedonia, Greece. Folia Zoologica. 54(3), 316-336.

Winfield, I. \& Nelson, J. S. (Eds.) (1991). Cyprinid Fishes: Systematics, biology and exploitation. (Vol. 3). Springer, Heidelberg. 